\title{
FAKTOR-FAKTOR YANG MEMENGARUHI STATUS PERFORMA PASIEN TUMOR INTRAKRANIAL DI RSUPN DR. CIPTO MANGUNKUSUMO
}

\author{
FACTORS INFLUENCING PERFORMANCE STATUS IN PATIENTS WITH INTRACRANIAL \\ TUMOR AT CIPTO MANGUNKUSUMO GENERAL HOSPITAL
}

Mariana Nur Laila, * Rini Andriani, ** Henry Riyanto Sofyan, *** Tiara Aninditha***

\begin{abstract}
Introduction: Patients diagnosed with malignancy have a long course of illness from diagnosis to treatment. Assessment of performance status (PS) is essential to give an overview of therapeutic readiness and patient's prognosis. Karnofsky Performance Scale is a PS assessment used widely in neurooncology patients. This instrument can assess functional impairment among patients. To this date, clinical factors in admission time that influences KPS in hospitalized intracranial tumor has not been researched.
\end{abstract}

Aim: To get an overview of KPS in hospitalized intracranial patients in Cipto Mangunkusumo General Hospital and to investigate factors that influence.

Methods: The design of this research was cohort retrospective. The research was done in Cipto Mangunkusumo General Hospital using secondary data in 2015-2016. The subjects of the research were patients with intracranial tumors. Demographic, clinical status in admission, pathological anatomy, and performance status data were acquired. The data were processed and presented descriptively and analytically. Independent predictors investigated using multivariate logistic regression.

Results: There were 68 subjects obtained in this research. As much as 35 (51.5\%) subject had primary intracranial tumor. As much as 58 (85.2\%) subjects aged <60 years old. As much as 51 (76.5\%) subjects had supratentorial tumor. Majority of subjects (70\%) had KPS score $<70$. Subjects with primary tumor had more cranial nerve palsy ( $p=0.021)$ and hemiparesis $(p=0.038)$. Decreased consciousness increased the risk of KPS score $<70$ by $5.2 x$ in the time of admission.

Discussion: Majority of subjects had KPS score <70. Decreased consciousness in the time of admission is an independent predictive factor that lowers KPS.

Keywords: Karnofsky Performance Scale, intracranial tumor, neurooncology, risk factors

\section{ABSTRAK}

Pendahuluan: Pasien keganasan memiliki perjalanan penyakit yang panjang mulai dari diagnosis hingga tata laksana. Kondisi pasien dapat sangat beragam, sehingga penting dilakukan pengkajian status performa untuk memberikan gambaran kesiapan terapi dan prognosisnya. Instrumen yang paling sering digunakan secara standar internasional adalah Karnofsky Performance Scale (KPS). Sejauh ini belum diketahui penggunaan KPS pada pasien tumor intrakranial, mengingat performa pasien yang tidak hanya disebabkan oleh keganasannya, namun juga kecacatan akibat dari lesinya.

Tujuan: Mendapatkan gambaran KPS pasien tumor intrakranial serta faktor-faktor yang memengaruhinya.

Metode: Penelitian kohort retrospektif terhadap pasien tumor intrakranial yang dirawat di RSUPN Dr. Cipto Mangunkusumo, Jakarta, pada tahun 2015-2016. Dilakukan pencatatan karakteristik demografik pasien, faktor klinis saat admisi, patologi anatomi, dan KPS. Data disajikan secara deskriptif dan analitik, faktor prediktor independen diinvestigasi menggunakan analisis multivariat regresi logistik.

Hasil: Didapatkan 68 subjek dalam penelitian ini dengan proporsi tumor primer dan sekunder sebanyak 33 dan 35 orang. Subjek perempuan lebih banyak pada kelompok tumor primer dan lebih sedikit pada tumor sekunder. Mayoritas subjek berusia $<60$ tahun $(85,2 \%)$, lokasi tumor di supratentorial $(76,5 \%)$, dan KPS masuk $<70(69,2 \%)$. Subjek dengan penurunan kesadaran saat masuk perawatan akan cenderung memiliki KPS $<70(p=0,005)$ dibanding faktor-faktor klinis lainnya dengan risiko 5,2x menyebabkan status performa yang rendah tersebut saat admisi.

Diskusi: Sebagian besar subjek memiliki nilai KPS $<70$. Penurunan kesadaran saat admisi merupakan faktor prediktif independen penurunan KPS.

Kata kunci: Faktor risiko, Karnofsky Performance Scale, neuroonkologi, tumor intrakranial

*SMF Neurologi RSUD Inche Abdoel Moeis, Samarinda-Peserta Fellowship Neuroonkologi Departemen Neurologi FK Universitas Indonesia/RSUPN Dr. Cipto Mangunkusumo, Jakarta; **SMF Neurologi RS Kanker Dharmais, Jakarta; ***Departemen Neurologi FK Universitas Indonesia/RSUPN Dr. Cipto Mangunkusumo, Jakarta. Korespondensi: dr.mariananl@gmail.com. 


\section{PENDAHULUAN}

Penyakit keganasan merupakan penyakit yang memerlukan penanganan komprehensif mulai dari penegakkan diagnosis hingga terapinya. Dalam penatalaksanaannya, diperlukan kesiapan baik fisik ataupun psikologis. Kesiapan tersebut dinilai dari performa. Performa adalah kemampuan seseorang untuk melakukan aktivitas harian termasuk bekerja dan perlu tidaknya pendampingan. Penilaian status performa ini dilakukan berdasarkan kemampuan fisik terbaik pasien didasarkan pada tingkatan fungsinya. ${ }^{1}$

Status fungsional pasien secara global digambarkan melalui status performa. Status tersebut digunakan untuk memutuskan terapi, evaluasi terapi, dan kemungkinan perawatan di rumah. Informasi prognosis yang akurat dapat membantu dokter memutuskan memulai atau melanjutkan terapi antikanker dan penatalaksanaan lanjutan. ${ }^{2}$ Pengkajian status performa yang sering digunakan adalah Karnofsky Performance Scale (KPS) dan Eastern Cooperative Oncology Group (ECOG)/WHO scale. ${ }^{3}$

KPS pertama kali dikembangkan pada tahun 1948 untuk mengevaluasi kemampuan pasien mentoleransi kemoterapi yang terdiri dari 11 kategori. ${ }^{4}$ Pengkajian status performa pada kasus neuroonkologi lebih banyak menggunakan KPS dibandingkan ECOG Scale. ${ }^{5}$ Dalam aplikasinya, tidak ada perbedaan bermakna dalam memprediksi kesintasan antara penggunaan KPS dan ECOG Scale pada kasus-kasus onkologi. ${ }^{2}$ KPS dapat digunakan untuk kasus tumor primer atau metastasis intrakranial. ${ }^{6}$

Tumor intrakranial menyebabkan gejala klinis berupa defisit neurologis pada sebagian besar penderitanya. Berbeda dengan keganasan sistemik, defisit neurologis tersebut tidak hanya dipengaruhi oleh derajat keganasan tumor, namun bervariasi tergantung letak dan ukuran tumornya. Oleh karena itu, pasien dengan tumor intrakranial dapat mengalami gangguan motorik maupun sensorik, nervus kranialis, maupun kognitif, serta kejang dan tanda-tanda peningkatan tekanan intrakranial (TIK) seperti penurunan kesadaran. ${ }^{7-8}$

Adanya kecacatan akibat tumor intrakranial ini akan memengaruhi status performa serta kualitas hidup pasien. Semakin rendah status performanya, semakin buruk kualitas hidup pasien. ${ }^{9}$ Selain itu, status performa yang semakin rendah akan berimplikasi terhadap terbatasnya terapi dan memperburuk faktor prognostik kesintasan pasien. Pada pasien tumor intrakranial, status performa sudah menurun pada saat diagnosis akibat defisit neurologisnya,${ }^{10}$ namun belum ada penelitian mengenai faktor-faktor yang menyebabkan penurunan KPS pada pasien tersebut.

\section{TUJUAN}

Mendapatkan gambaran KPS pada pasien tumor serta faktor-faktor yang memengaruhinya.

\section{METODE}

Penelitian ini merupakan penelitian kohort retrospektif yang dilakukan di RSUPN Dr. Cipto Mangunkusumo, Jakarta. Penelitian dilakukan dengan melihat, mengambil data dari rekam medis pada bulan Januari 2015-Desember 2016. Pasien yang dilibatkan dalam penelitian ini memiliki kriteria inklusi diatas 18 tahun serta memiliki hasil biopsi pada tumor otak atau pada organ primer yang metastasis intrakranial. Subjek dilakukan pencatatan data demografis dan klinis saat admisi serta KPS saat perawatan di RS yang dibagi menjadi $<70$ dan $\geq 70$.

Dilakukan uji Chi-square untuk analisis bivariat terhadap faktor-faktor yang memengaruhi KPS saat perawatan. Jika uji Chi-square tidak memenuhi syarat maka dilakukan uji Fisher. Analisis multivariat dilakukan pada kovariat yang memiliki $\mathrm{p}<0,25$ berdasarkan analisis bivariat. Uji multivariat regresi logistik dilakukan untuk mengetahui faktor independen prediktif yang memengaruhi KPS saat admisi rawat.

\section{HASIL}

Penelitian ini melibatkan 68 subjek (Tabel 1) dengan proporsi tumor primer dan sekunder sebanyak 33 dan 35 orang. Subjek perempuan lebih banyak pada kelompok tumor primer dan lebih sedikit pada tumor sekunder. Mayoritas subjek berusia $<60$ tahun $(85,2 \%)$, lokasi tumor di supratentorial $(76,5 \%)$, dan KPS masuk $<70(69,2 \%)$.

Gejala subjek yang paling dominan adalah nyeri kepala (Tabel 2), baik kelompok tumor primer maupun sekunder $(69,7 \%$ dan $62,9 \%)$, serta 
Tabel 1. Karakteristik Tumor pada Subjek $(n=68)$

\begin{tabular}{|c|c|c|c|c|}
\hline \multirow{3}{*}{ Variabel } & \multicolumn{2}{|c|}{ Tumor Intrakranial } & \multirow[b]{2}{*}{ Total } & \multirow{3}{*}{$\mathbf{p}$} \\
\hline & $\begin{array}{l}\text { Primer } \\
(n=33)\end{array}$ & $\begin{array}{c}\text { Sekunder } \\
(\mathrm{n}=35)\end{array}$ & & \\
\hline & n (\%) & n (\%) & n (\%) & \\
\hline \multicolumn{5}{|l|}{ Jenis Kelamin } \\
\hline - Laki-laki & $15(22)$ & $21(30,9)$ & $36(52,9)$ & 0,649 \\
\hline - Perempuan & $18(26,5)$ & $14(20,6)$ & $32(47,1)$ & \\
\hline \multicolumn{5}{|l|}{ Usia } \\
\hline - $<60$ & $29(42,6)$ & $29(42,6)$ & $58(85,2)$ & $0,735^{*}$ \\
\hline - $\geq 60$ & $4(5,8)$ & $6(8,8)$ & $10(14,8)$ & \\
\hline \multicolumn{5}{|l|}{ Letak Tumor } \\
\hline - Supratentorial & $27(39,7)$ & $25(36,8)$ & $53(76,5)$ & 0,313 \\
\hline - Infratentorial & $6(8,8)$ & $10(14,7)$ & $16(23,5)$ & \\
\hline \multicolumn{5}{|l|}{ KPS Masuk } \\
\hline - $<70$ & $22(32,4)$ & $25(36,8)$ & $47(69,2)$ & 0,671 \\
\hline - $\geq 70$ & $11(16,2)$ & $10(14,7)$ & $21(30,9)$ & \\
\hline
\end{tabular}

*Uji Fisher exact; KPS: Karnofsky Performance Scale.

hemiparesis dan paresis nervus kranialis. Sebanyak 42,6\% subjek mengalami papiledema dan 30,9\% penurunan kesadaran yang menunjukkan efek desak ruang dari tumor. Terdapat perbedaan proporsi bermakna pasien dengan paresis nervus kranialis $(84,8 \%$ vs $60 \%)$ dan hemiparesis $(75,8 \%$ vs $51,4 \%)$ pada tumor intrakranial primer dan sekunder. Subjek dengan tumor intrakranial primer lebih banyak disertai dengan paresis nervus kranialis $(p=0,021)$ dan hemiparesis $(\mathrm{p}=0,038)$.

Tabel 3 menunjukkan bahwa subjek dengan penurunan kesadaran saat masuk perawatan akan cenderung memiliki KPS $<70(p=0,005)$ dibanding faktor-faktor klinis lainnya.

Berdasarkan hasil bivariat pada Tabel 3, variabel yang memenuhi kriteria $(\mathrm{p}<0,25)$ dianalisis lebih lanjut secara multivariat. Penurunan kesadaran saat admisi merupakan faktor prediktor independen KPS $<70$ saat perawatan. Pasien dengan penurunan kesadaran berisiko 5,26 kali lebih besar dibandingkan pasien sadar memiliki KPS $<70(\mathrm{p}=0,08)$.

\section{PEMBAHASAN}

Penelitian merupakan studi kohort retrospektif terhadap pasien dengan tumor intrakranial yang dirawat oleh Divisi Neuroonkologi di RSUPN Dr. Cipto Mangunkusumo, Jakarta pada bulan Januari 2015 hingga Desember 2016. Mayoritas subjek dengan tumor primer adalah perempuan, sesuai dengan populasi umum tumor intrakranial. ${ }^{11}$ Namun, subjek dengan metastasis intrakranial lebih banyak dialami oleh laki-laki dibandingkan perempuan, sesuai penelitian Butovski dkk. ${ }^{12}$

Subjek tumor intrakranial baik primer maupun sekunder paling banyak ditemukan pada usia $<60$ tahun (88\% dan 83\%). Wagman-Ostrosky mendapatkan rerata usia pasien untuk tumor intrakranial khususnya glioblastoma adalah 45,7 tahun. ${ }^{13}$ Letak tumor terutama di supratentorial $(76,5 \%)$ sebagai area otak yang paling luas dan paling banyak pembuluh darahnya. Schiff D menyebutkan 95\% letak tumor pada low grade glioma adalah supratentorial. ${ }^{14}$

Mayoritas subjek memiliki status performa yang rendah, yaitu KPS $<70$ saat perawatan di RS, baik pada tumor intrakranial primer $(67,7 \%)$ ataupun pada sekunder $(71,4 \%)$. Namun, tidak ada perbedaan bermakna antara kedua nilai ini. Nilai tengah atau cut-off point untuk KPS dalam penelitian ini adalah 70 , sebagai nilai toleransi yang baik untuk menerima standar terapi kanker. Adapun nilai KPS $<70$ menyebabkan angka kesintasan rendah. ${ }^{15-16}$ Jang dkk menyatakan bahwa semakin rendah KPS, semakin rendah median kesintasan pada pasien. ${ }^{2}$ Menurut Panciroli dkk, KPS sangat penting dalam keputusan tata laksana. ${ }^{17}$ Semakin rendah KPS pasien, semakin terbatas tata laksana yang dapat diberikan. Perawatan selama di rumah sakit diharapkan dapat memperbaiki status fungsional penderita kanker dengan terapi yang diberikan. ${ }^{13,15-16,18}$

Gejala klinis yang paling banyak ditemukan dalam penelitian ini adalah nyeri kepala, hemiparesis, 
Tabel 2. Karakteristik Subjek Berdasarkan Defisit Neurologis $(n=68)$

\begin{tabular}{|c|c|c|c|c|}
\hline \multirow{3}{*}{ Variabel } & \multicolumn{3}{|c|}{ Tumor Intrakranial } & \multirow{3}{*}{$\mathbf{p}$} \\
\hline & $\begin{array}{c}\text { Primer } \\
(n=33)\end{array}$ & $\begin{array}{c}\text { Sekunder } \\
(\mathrm{n}=35)\end{array}$ & Total & \\
\hline & n (\%) & n (\%) & n (\%) & \\
\hline \multicolumn{5}{|l|}{ Nyeri Kepala } \\
\hline - $\quad \mathrm{Ya}$ & $23(33,8)$ & $22(32,4)$ & $45(64,1)$ & 0,551 \\
\hline - $\quad$ Tidak & $10(14,7)$ & $13(19,1)$ & $23(30,9)$ & \\
\hline \multicolumn{5}{|l|}{ Kejang } \\
\hline - $\quad \mathrm{Ya}$ & $11(16,2)$ & $13(19,1)$ & $24(35,3)$ & 0,743 \\
\hline - $\quad$ Tidak & $22(32,4)$ & $22(32,4)$ & $44(64,8)$ & \\
\hline \multicolumn{5}{|l|}{ Muntah } \\
\hline - $\quad \mathrm{Ya}$ & $12(17,6)$ & $6(8,9)$ & $18(26,5)$ & 0,073 \\
\hline - $\quad$ Tidak & $21(30,9)$ & $29(42,6)$ & $50(73,5)$ & \\
\hline \multicolumn{5}{|l|}{ Penurunan Kesadaran } \\
\hline - $\quad \mathrm{Ya}$ & $14(20,6)$ & $16(23,6)$ & $30(30,9)$ & 0,671 \\
\hline - $\quad$ Tidak & $19(27,9)$ & $19(27,9)$ & $38(55,8)$ & \\
\hline \multicolumn{5}{|l|}{ Paresis N. Kranial } \\
\hline - $\quad \mathrm{Ya}$ & $28(41,1)$ & $21(30,9)$ & $49(72)$ & 0,021 \\
\hline - $\quad$ Tidak & $5(7,4)$ & $14(20,6)$ & $46(28)$ & \\
\hline \multicolumn{5}{|l|}{ Papiledema } \\
\hline - $\quad \mathrm{Ya}$ & $12(17,6)$ & $17(25)$ & $29(42,6)$ & 0,309 \\
\hline - $\quad$ Tidak & $21(30,9)$ & $18(26,5)$ & $39(57,4)$ & \\
\hline \multicolumn{5}{|l|}{ Hemiparesis } \\
\hline - $\quad \mathrm{Ya}$ & $25(36,8)$ & $18(26,5)$ & $43(63,3)$ & 0,038 \\
\hline - $\quad$ Tidak & $8(11,8)$ & $17(25)$ & $25(36,7)$ & \\
\hline
\end{tabular}

paresis nervus kranialis, papiledema, dan penurunan kesadaran. Nyeri kepala banyak ditemukan pada tumor intrakranial primer $(69,7 \%)$ dan pada tumor sekunder (62,9\%). Hal ini lebih tinggi dibandingkan epidemiologi secara umum, yaitu nyeri kepala dikeluhkan sekitar $50 \%$ pada kasus tumor intrakranial. ${ }^{12}$ Nyeri ini dapat terjadi karena bertambahnya tekanan intrakranial akibat massa dimanapun letaknya, sehingga terjadi peregangan meningen yang merangsang reseptor nyeri disekitarnya. ${ }^{11}$

Selain nyeri kepala, subjek juga mengalami papiledema, penurunan kesadaran, dan muntah akibat peningkatan tekanan intrakranial (TIK). Dalam penelitian ini, tidak ditemukan hubungan antara tandatanda peningkatan TIK tersebut sebagai persentasi awal dengan KPS selama perawatan. Hal ini dapat dijelaskan akibat efek kortikosteroid yang diberikan sebagai tata laksana awal pada edema vasogenik akibat tumor yang dapat menurunkan TIK dan memperbaiki gejala neurologis, sehingga menaikkan kembali KPS pasien. ${ }^{19}$

Kejang dapat disebabkan oleh efek desak ruang pada korteks. ${ }^{11,14}$ Kejang ditemukan pada $35,3 \%$ subjek penelitian ini, yang angkanya memang sangat bervariasi hingga $70 \%$ pada kasus tumor intrakranial. ${ }^{20}$ Dalam penelitian ini, tidak ditemukan hubungan antara riwayat kejang dengan penurunan KPS saat perawatan. Hal ini sejalan dengan Maschio dkk yang menyatakan bahwa kejang pada tumor otak tidak memengaruhi KPS. Tidak ada perbedaan bermakna pemberian obat antiepilepsi (OAE), durasi kejang, dan jumlah kejang pada pasien tumor intrakranial. ${ }^{21}$

Subjek dengan tumor intrakranial primer lebih banyak disertai dengan paresis nervus kranialis $(\mathrm{p}=0,021)$ dan hemiparesis $(\mathrm{p}=0,038)$. Pada peningkatan volume intrakranial, tekanan akan diteruskan ke segala arah, sehingga terjadi peregangan meningen, termasuk saraf kranial yang melintasinya seperti 
Tabel 3. Faktor Klinis saat Admisi yang Memengaruhi KPS $(n=68)$

\begin{tabular}{|c|c|c|c|}
\hline \multirow{2}{*}{ Variabel } & \multicolumn{2}{|c|}{ KPS Masuk } & \multirow[b]{2}{*}{ p } \\
\hline & $<70$ & $\geq 70$ & \\
\hline \multicolumn{4}{|l|}{ Jenis Kelamin } \\
\hline - Laki-laki & 22 & 7 & 0,299 \\
\hline - Perempuan & 25 & 14 & \\
\hline \multicolumn{4}{|l|}{ Usia } \\
\hline - $\quad<60$ & 39 & 19 & 0,42 \\
\hline - $\quad \geq 60$ & 8 & 2 & \\
\hline \multicolumn{4}{|l|}{ Jenis Tumor } \\
\hline - Primer & 22 & 11 & 0,671 \\
\hline - Metastasis & 25 & 10 & \\
\hline \multicolumn{4}{|l|}{ Letak Tumor } \\
\hline - Supratentorial & 34 & 18 & $0,355^{*}$ \\
\hline - Infratentorial & 13 & 3 & \\
\hline \multicolumn{4}{|l|}{ Tipe Tumor } \\
\hline - Astrositoma & 10 & 4 & $1,0 *$ \\
\hline - Meningioma & 8 & 3 & \\
\hline \multicolumn{4}{|l|}{ Defisit Neurologis } \\
\hline \multicolumn{4}{|l|}{ - Nyeri Kepala } \\
\hline$\circ \mathrm{Ya}$ & 31 & 14 & 0,954 \\
\hline o Tidak & 16 & 7 & \\
\hline \multicolumn{4}{|l|}{ - Kejang } \\
\hline$\circ \mathrm{Ya}$ & 18 & 6 & 0,438 \\
\hline o Tidak & 29 & 15 & \\
\hline \multicolumn{4}{|l|}{ - Muntah } \\
\hline$\circ \mathrm{Ya}$ & 12 & 6 & 0,793 \\
\hline o Tidak & 35 & 15 & \\
\hline \multicolumn{4}{|l|}{ - Penurunan Kesadaran } \\
\hline$\circ \mathrm{Ya}$ & 26 & 4 & 0,005 \\
\hline o Tidak & 21 & 17 & \\
\hline \multicolumn{4}{|l|}{ - Paresis N. Kranialis } \\
\hline$\circ \mathrm{Ya}$ & 34 & 15 & 0,938 \\
\hline o Tidak & 13 & 6 & \\
\hline \multicolumn{4}{|l|}{ - Papiledema } \\
\hline$\circ \mathrm{Ya}$ & 23 & 6 & 0,117 \\
\hline o Tidak & 24 & 15 & \\
\hline \multicolumn{4}{|l|}{ - Hemiparesis } \\
\hline$\circ \mathrm{Ya}$ & 31 & 12 & 0,486 \\
\hline o Tidak & 16 & 9 & \\
\hline
\end{tabular}

*Fisher exact test.

nervus abdusens, sehingga dapat terjadi diplopia. Bila mengenai nervus optikus terjadi papiledema yang akan menyebabkan keluhan pandangan buram. ${ }^{11}$

Hemiparesis terjadi bila mengenai jaras motorik di serebri. ${ }^{14}$ Tumor intrakranial primer jumlah lesinya adalah soliter dan cukup besar sehingga meyebabkan efek desak ruang akibat edema dan massa tumornya sendiri. Adapun tumor metastasis jumlah lesinya bisa lebih banyak namun berukuran kecil sehingga efek desak ruang belum nampak, kecuali bila massa tumor intrakranial membesar disertai edema peritumoral yang besar pula, sehingga dapat mengakibatkan paresis nervus kranialis dan hemiparesis.

Amidei dkk menyatakan bahwa hemiparesis pada tumor otak merupakan salah satu defisit yang menurunkan status fungsional. ${ }^{10}$ Namun, dalam penelitian ini hemiparesis saat masuk RS tidak berhubungan dengan KPS yang rendah saat perawatan. Hal ini menunjukkan bahwa terdapat faktor klinis selain hemiparesis yang berperan dalam menurunkan KPS pada tumor otak.

Penurunan kesadaran saat masuk rumah sakit memengaruhi KPS. Skala Koma Glasgow yang rendah menyebabkan subjek lebih banyak berada di tempat tidur dengan nilai KPS $<70$. Dalam penelitian ini, penurunan kesadaran memengaruhi KPS saat perawatan. Dari hasil analisis multivariat dijelaskan bahwa pasien dengan penurunan kesadaran saat masuk RS berisiko 5,26 kali menyebabkan KPS saat perawatan $<70$. Penurunan kesadaran merupakan salah satu tanda peningkatan TIK. Penurunan kesadaran dapat terjadi jika TIK sudah sangat tinggi dan menekan pusat kesadaran di batang otak, sehingga memerlukan waktu lebih lama untuk menaikkan kembali derajat fungsional pasien.

Dalam penelitian ini, tidak ditemukan perbedaan KPS pada berbagai jenis histologi tumor. Hal ini sesuai oleh Perkins dkk yang menyatakan bahwa tidak ada perbedaan klinis antara jenis tumor di otak. Lokasi anatomis dan besar tumor menentukan tanda dan gejala yang dirasakan pasien tanpa membedabedakan jenis histologinya. ${ }^{7}$

Penelitian ini merupakan penelitian pertama yang meneliti faktor-faktor klinis yang berpengaruh pada KPS pasien tumor saat perawatan. Dari penelitian ini, didapat gambaran karakteristik tumor intrakranial saat masuk RS dan KPS pada saat perawatan. Namun terdapat beberapa keterbatasan dalam penelitian ini diantaranya adalah tidak adanya 
faktor penyulit sistemik pada subjek dan status kognitif yang mungkin juga dapat memengaruhi status performa subjek.

\section{KESIMPULAN}

Mayoritas pasien dengan tumor intrakranial mengalami KPS yang rendah $(<70)$. Pasien dengan penurunan kesadaran saat admisi berisiko 5,26 kali menurunkan KPS saat perawatan.

\section{DAFTAR PUSTAKA}

1. Martin RC, Gerstenecker A, Nabors LB, Marson DC, Triebel KL. Impairment of medical decisional capacity in relation to Karnofsky performance status in adults with malignant brain tumor. Neurooncol Pract. 2015;2(1):13-9.

2. Jang RW, Caraiscos VB, Swami N, Banerjee S, Mak E, Kaya E, dkk. Simple prognostic model for patients with advanced cancer based on performance status. J Oncol Pract. 2014;10(5):e335-41.

3. Atkinson TM, Andreotti CF, Roberts KE, Saracino RM, Hernandez M, Basch E. The level of association between functional performance status measures and patient-reported outcomes in cancer patients: a systematic review. Support Care Cancer. 2015;23(12):3645-52.

4. Cheng S, Qureshi M, Pullenayegum E, Haynes A, Chan KK. Do patients with reduced or excellent performance status derive the same clinical benefit from novel systemic cancer therapies? A systematic review and meta-analysis. ESMO Open. 2017;2(4):e000225.

5. Peus D, Newcomb N, Hofer S. Appraisal of the Karnofsky performance status and proposal of a simple algoritmic system for evaluation. BMC. 2013;13(72).

6. Reali A, Allis S, Girardi A, Verna R, Bianco L, Redda MG. Is Karnofsky performance status correlate with better overall survival in palliative conformal whole brain radiotherapy? our experience. Indian J Palliat Care. 2015;21(3):311-6.

7. Perkins A, Liu G. Primary brain tumors in adult: diagnosis and treatment. Am Fam Physician. 2016;93(3):211-7.

8. Davies E, Clarke C. Early symptoms of brain tumours. J Neurol Neurosurg Psychiatry. 2004;75(8):1205-6.

9. BuneviciusA, Tamasauskas S, Deltuva V, Tamasauskas A, Radziunas A, Bunevicius R. Predictors of health- related quality of life in neurosurgical brain tumor patients: focus on patient-centered perspective. Acta Neurochir (Wien). 2014;156(2):367-74.

10. Amidei C, Kushner DS. Clinical implications of motor deficits related to brain tumors(dagger). Neurooncol Pract. 2015;2(4):179-84.

11. Aninditha T, Ranakusuma TAS. Tumor otak primer. Dalam: Aninditha T, Wiratman W, penyunting. Buku Ajar Neurologi. Jakarta: Penerbit Kedokteran Indonesia; 2017.

12. Butovski NA. Epidemiology and diagnosis of brain tumors. Continuum (Minneap Minn). 2015;21(2):30113.

13. Wagman OT, Reynoso NN, Mejia PSI, Sanchez CTE, Alvarez GRM, Vidal MS, dkk. Clinical prognostic factors in adults with astrocytoma: historic cohort. Clin Neurol Neurosurg. 2016;146:116-22.

14. Schiff D. Low grade glioma. Continuum (Minneap Minn). 2017;23(6):1564-79.

15. Alvarez DEBS, Alvarez VMA, Balbin M, Sanchez PA, Alvarez A, Martino GJ. Prognostic factors and survival study in high-grade glioma in the elderly. $\mathrm{Br}$ J Neurosurg. 2016;30(3):330-6.

16. Mazaris P, Hong X, Altshuler D, Schultz L, Poisson LM, Jain R, dkk. Key determinants of short-term and long-term glioblastoma survival: a 14-year retrospective study of patients from the Hermelin Brain Tumor Center at Henry Ford Hospital. Clin Neurol Neurosurg. 2014;120:103-12.

17. Panciroli C, Estival A, Lucente G, Velarde JM, Garcia R, Laia V, dkk. ECOG or Karnofsky performance status to assess functionality in glioblastoma patients among different observers. J Mol Biomark Diagn. 2017;:S2:032.

18. Nayak L, Reaedon DA. High grade gliomas. Continuum (Minneap Minn). 2017;23(6):1548-63.

19. Andriani R, Citra I. Tumor otak sekunder (metastasis). Dalam: Aninditha T, Andriani R, Malueka RG, penyunting. Buku Ajar Neuroonkologi. Jakarta: Penerbit Kedokteran Indonesia; 2019.

20. Pruitt AA. Epidemiology, treatment, and compilcations of central nervous system metastases. Continuum (Minneap Minn). 2017;23(6):1580-600.

21. Maschio M, Sperati F, Dinapoli L, Vidiri A, Fabi A, Pace A, dkk. Weight of epilepsy in brain tumor patients. J Neurooncol. 2014;118(2):385-93. 